\title{
STUDY TIME OF HIGH SCHOOL PUPILS.
}

By Marie Gugle, Supervisor of High Schools, Columbus, Ohio.

This year, when the course of study for grades seven to twelve is being revised, it seened appropriate to investigate the time spent in preparation of lessons, either in or out of school by pupils of high school grade, in order that any inequalities might be adjusted. The results of this investigation may be of interest to the readers of School Science and Mathematics.

Each high school pupil was asked to list his subjects and give the approximate time, correct to the nearest fifteen minutes, spent in daily preparation. Since the number reporting is so large (almost 3,500), most inaccuracies will be offset; so these statistics are as reliable as any such can be.

These lists were carefully tabulated for each high school, for boys and girls separately. The accompanying table shows the totals for all the schools. The figures refer to the number of pupils spending. approximately the time given at the top of the column in daily preparation of the subject listed on the same line at the left. For example, eighty-three pupils spend fifteen minutes daily in preparing first year English; fifty-six pupils spend an hour and a half daily on fourth year Latin. The figures at the right give the total number studying the subject as per reports. There were 3,227 studying English; 1,601, Latin; and 2,18\%, science.

Forty-five minutes is probably a fair time to devote to the study of a lesson in addition to an equal period of recitation. In English, the numbers center on the 45 -minute period with 1,242 , but 955 take only thirty minutes and about two-thirds as many, an hour.

Latin centers around the hour, with large numbers spending even more time. In the senior year the center is on an hour and a half, and many listed under the hour and three-quarters or more, really reported two or two and a half hours. In English, out of a total of $3,22 \%$, only twenty-two take the maximum time; in Latin, out of half that number (or 1,601), one hundred seventeen take the maximum. For other subjects, compare the figures in the table.

Science and mathematics both center at forty-five minutes; but in each case the number at the half hour is about double that at the hour, which shows that, in these subjects, the tendency is to- 
wards a period less than forty-five minutes rather than more; but in Latin and German the tendency is toward a longer period. History is about evenly balanced, with 338 for the half hour and 330 for the hour.

Columbus High School.s.

Time Spent in Preparation, With Number of Pupils for Each 15-Minute

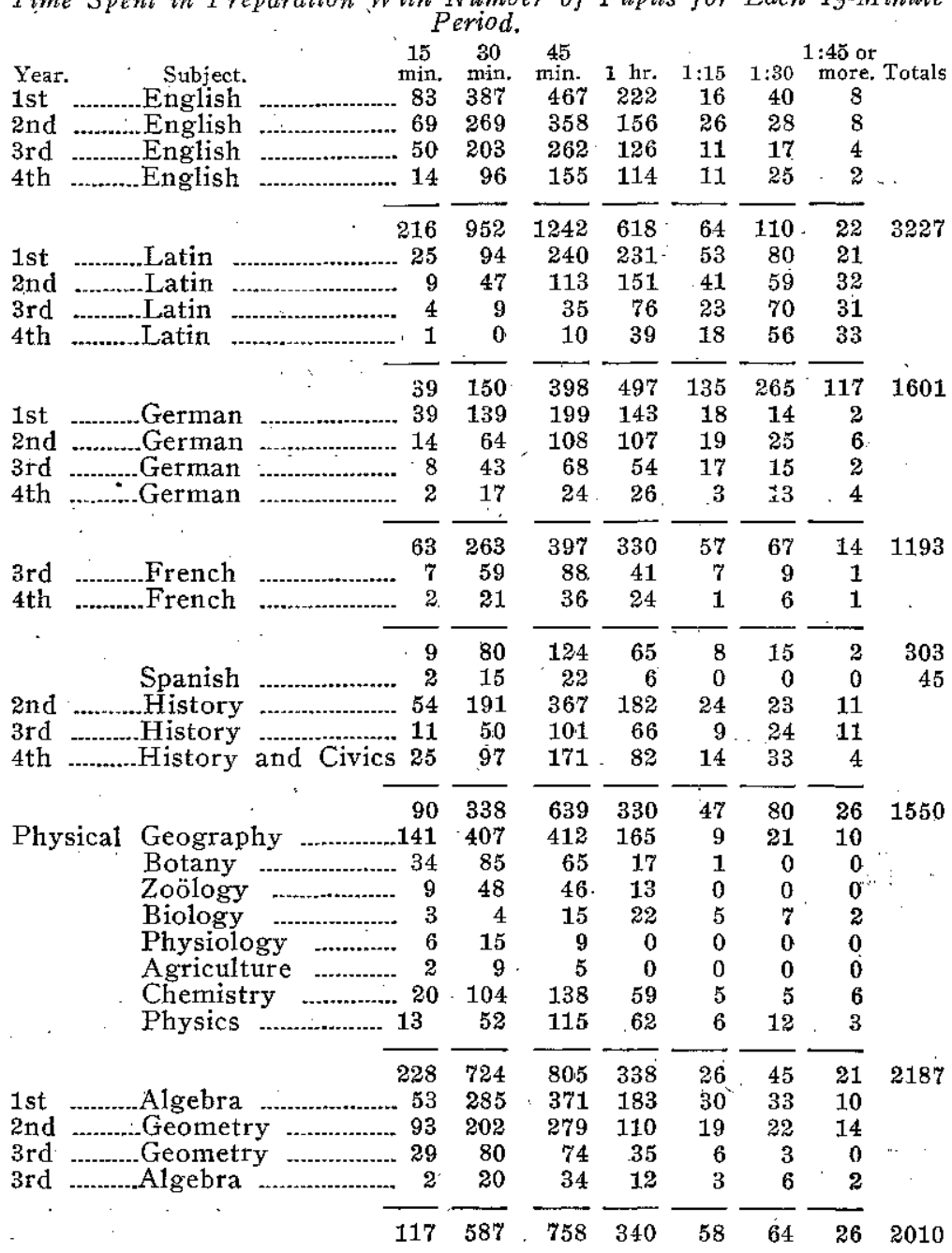

Some one may ask what conclusions may be drawn from these figures and of what use are they. Different persons will draw different conclusions; but one that seems evident is that Latin in all years, and German in some, are demanding too great a 
share of the pupils' time. The Latin course has not been changed since the time when it was one of three studies, instead of one of four, and when the pupil had very few demands made upon his time and energy, other than those of his studies. But conditions have changed. Many other activities are now considered a necessary part of his education. In the revised course of study, based on the six-and-six organization, this matter can be adjusted. It is far better to adapt the course in Latin to present conditions, than to have it lose its position entirely.

The one subject that has had to bear the accusation of being the hardest and the one chiefly responsible for pupils' leaving high school, is mathematics. That charge does not seem to be warranted, since this table shows that 1,522 pupils prepare their mathematics in three-quarters of an hour or less, and only 488 spend an hour or more on it.

Since nearly all of the subjects center rightly around the 45 minute period, I believe we can safely conclude that, on the whole, our pupils are not overworked; that is, the amount of work required is fair, and other reasons must be found to explain the occasional breakdown, usually attributed to overwork, such as the strain under which the work is done, unwise division of pupils' time, or indiscretions in diet and social activities.

\section{MUDDIEST OF RIVERS.}

The Missouri is the muddiest river in the Mississippi Valley; it carries more silt than any other large river in the United States except possibly the Rio Grande and the Colorado. For every square mile of country drained, it carries downstream 381 tons of dissolved and suspended matter each year. In other. words, the river gathers annually from the country that it drains more than $123,000,000$ tons of silt and soluble matter, some of which it distributes over the flood plans below to form productive agricultural lands, but most of which finds its way at last to the Gulf of Mexico.

It is by means of data of this kind that geologists compute the rate at which the lands are being eroded away. It has been shown that Missouri River is lowering the surface of the land drained by it at the rate of one foot in $.6,036$ years. The surface of the United States as a whole is now being worn down at the rate of one foot in 9,120 years. It has been estimated that if this erosive action of the streams of the United States could have been concentrated on the Isthmus of Panama it would have dug in seventy-three days the canal which has just been completed, after ten years' work, with the most powerful appliances yet devised by man.-Overland Guidebook, Bulletin 6I2, U. S. Geological Survey.

The annual statement of the Geological Survey on sand and gravel for 1914 is now available for distribution. During the year 79,281,735 short tons of sand and gravel, having a value of $\$ 23,846,999$, were produced in the United States. 